\title{
A report on the large measles outbreak in Lyon, France, 2010 to 2011
}

C Huoi $^{1}$, J S Casalegno², T Bénet ${ }^{1,3}$, A Neuraz ${ }^{1}$, G Billaud², D Eibach ${ }^{4}$, Y Mekki², R Rudigoz ${ }^{5}$, J Massardier ${ }^{5}$, C Huissoud $^{5}$, M $^{2}$

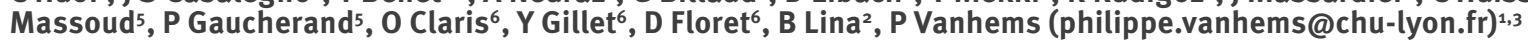

1. Infection Control Unit, Edouard Herriot Hospital, Hospices Civils de Lyon, Lyon, France

2. Virology Department, Centre de Biologie et Pathologie Est, Hospices Civils de Lyon, Lyon, France

3. Epidemiology and Public Health Group, CNRS UMR 5558, University of Lyon 1, Lyon, France

4. European Public Health Microbiology Training Programme (EUPHEM), European Centre for Disease Prevention and Control, Stockholm, Sweden

5. Gynecology Obstetrics Department, Hospices Civils de Lyon, Lyon, France

6. Pediatrics Department, Hospices Civils de Lyon, Lyon, France

MHuoi C, Casalegno JS, Bénet T, Neuraz A, Billaud G, Eibach D, Mekki Y, Rudigoz R, Massardier J, Huissoud C, Massoud M, Gaucherand P, Claris O, Gillet Y, Flore D, Lina B, Vanhems P. A report on the large measles outbreak in Lyon, France, 2010 to 2011. Euro Surveill. 2012;17(36):pii=20264. Available online: http://www. eurosurveillance.org/ViewArticle.aspx?Articleld=20264

Article submitted on 16 January 2012 / published on 6 September 2012

In 2010 and 2011, the city of Lyon, located in the Rhône-Alpes region (France), has experienced one of the highest incidences of measles in Europe. We describe a measles outbreak in the Lyon area, where cases were diagnosed at Lyon University hospitals (LUH) between 2010 and mid-2011. Data were collected from the mandatory notification system of the regional public health agency, and from the virology department of the LUH. All patients and healthcare workers who had contracted measles were included. Overall, 407 cases were diagnosed, with children of less than one year of age accounting for the highest proportion ( $n=129,32 \%$ ), followed by individuals between 17 and 29 years-old $(n=126,31 \%)$. Of the total cases, 72 $(18 \%)$ had complications. The proportions of patients and healthcare workers who were not immune to measles were higher among those aged up to 30 years. Consequently, women of childbearing age constituted a specific population at high risk to contract measles and during this outbreak, 13 cases of measles, seven under 30 years-old, were identified among pregnant women. This study highlights the importance of being vaccinated with two doses of measles vaccine, the only measure which could prevent and allow elimination of the disease.

\section{Introduction}

Measles is a one of the most highly contagious diseases. It is spread through respiratory droplets so that people in contact with the virus, who are not vaccinated or not immune due to prior infection, are at high risk of catching the disease. In France, vaccination against measles was first introduced in the vaccination programme in 1983 , with a single dose for infants aged 12-15 months. The vaccination schedule was subsequently modified in 1996, whereby two doses of vaccine against measles were recommended, with the first dose still at 12-15 months. The second dose was first administered at 11-13 years of age in 1996, then at 3-6 years of age from 1997 [1]. Since 2005, the first dose is recommended at the age of 12 months and the second dose at the age of 13-24 months [1]. A catch up vaccination is recommended for individuals who did not receive two vaccine doses. Earlier vaccination is recommended for infants who are attending a daycare centre, with in this case, the first dose administered at nine months of age and second dose at 12-15 months of age.

Measles cases were sporadic in France until 2008. Since the beginning of the year 2008, France has experienced successive measles wave epidemics [2-4]. The third wave was the largest and took place from October 2010 to April 2011 in the whole country, with the highest incidence in the south-east regions of France. Since 2008, measles are also spreading out of control in many other parts of Europe, such as for example Romania, Italy, Belgium or Switzerland [5-8]. Nevertheless, France appears to be the most affected, with more than half of the European cases [9]. Measles have been mandatorily notifiable in France since 2005. Healthcare practitioners, clinicians and biologists in laboratories have to report each suspected or confirmed case using a standardised form. Between January 2008 and April 2011, more than 18,000 measles cases were reported to the French Institute for Public Health Surveillance (Institut de Veille Sanitaire). These included 10 deaths, among which nine cases aged less than 30 years-old. Neurological complications affected 26 of the total measles' cases while 808 had severe pulmonary infections. About 4,000 patients with measles were hospitalised $[2,10]$. The high burden of the disease in teenagers and young adults under the age of 30 years [2,3] besides children (up to 16 years-old) is a new xmain feature of this reemerging disease. Young women are also a specifically exposed population, in so far as they are at high risk to contract measles but cannot be vaccinated during pregnancy. 
The Rhône-Alpes region has been the most affected area for measles in France $[2,11]$, with an incidence of 97.9 measles cases per 100,000 population between October 2010 and September 2011. Lyon is the biggest city in this region, with about 475,000 inhabitants registered in 2008. Lyon University Hospitals (LUH) are the main hospitals in Lyon and form the second largest hospital group in France. The objective of this study was to describe this large measles outbreak through notified cases diagnosed in LUH. The survey also presents a focus on pregnant women who when exposed while not immune are at higher risk of complications.

\section{Methods}

\section{Setting}

A prospective surveillance of measles cases was instituted in LUH from 1 January 2010. For the present study, data were collected between 1 January 2010 and 8 July 2011 according to the date of disease onset. LUH form the largest group of public hospitals in the town of Lyon. Our data concerned the four main hospitals of the group: hôpital Edouard Herriot, Centre hospitalier Lyon Sud, Groupement hospitalier Nord and hôpital Femme-Mère-Enfant. The last one received children and pregnant women. For the present report, we analysed two different data sources: (i) surveillance of measles cases through all the mandatory notifications conducted by one of the LUH and (ii) virological surveillance through tested samples derived from patients and healthcare workers (HCW).
Surveillance of measles cases notified by the Lyon university hospitals

The surveillance of patients diagnosed with measles during the outbreak in LUH was performed using data from mandatory notification which was available from the regional public health authorities database (Agence Régionale de Santé de Rhône-Alpes). Clinical suspected cases were defined as having fever $\geq 38.5^{\circ} \mathrm{C}$, maculopapular rash, and at least one of the following signs: conjunctivitis, coryza, cough, Koplik's sign. Laboratory-confirmed cases were clinical suspected cases with biological confirmation: specific IgM detected in saliva or serum and/or seroconversion with at least a four-fold increase of IgG titres and/or positive polymerase chain reaction (PCR) for measles virus. Epidemiologically-confirmed cases were defined as clinical cases who had had contact with laboratoryconfirmed cases 7-18 days before onset of symptoms.

\section{Virological surveillance of patients and healthcare workers}

Data about the viro-immunological status were extracted from the hospital virological-based surveillance database. This surveillance concerned patients or HCW tested for measles IgM and/or IgG and/or measles virus by PCR in LUH. The patients were tested either because: (i) they were clinically diagnosed with measles, or (ii) they were exposed to a measles case, or (iii) they were potentially susceptible. The group of HWC represented a selected group of all the employees of LUH. These HCW were tested either because: (i) they

\section{FIGURE 1}

Measles cases diagnosed in Lyon University Hospitals, measles outbreak in Lyon, France, 1 January 2010-8 July 2011 $(\mathrm{n}=407)$

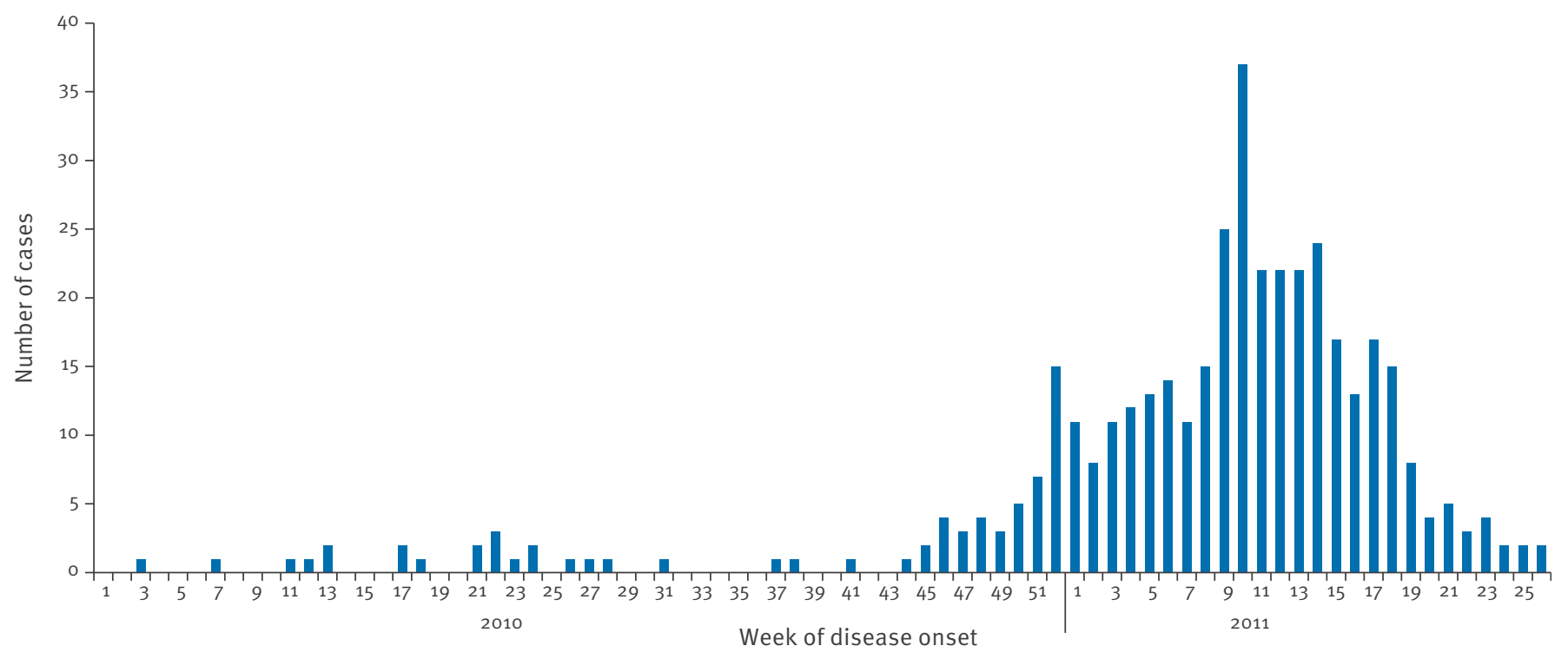


Characteristics of cases diagnosed with measles in Lyon University Hospitals, France, 1 January 2010-8 July 2011 (n=407)

\begin{tabular}{|c|c|c|c|}
\hline \multirow[t]{2}{*}{ Characteristics } & $\begin{array}{l}\text { Adults }>16 \text { years-old } \\
\qquad(\mathrm{n}=181)\end{array}$ & $\begin{array}{c}\text { Children } \leq 16 \text { years-old } \\
\qquad(\mathrm{n}=226)\end{array}$ & $\begin{array}{l}\text { Overall } \\
(n=407)\end{array}$ \\
\hline & $\mathrm{n} / \mathrm{N}(\%)^{\mathrm{a}}$ & $\mathrm{n} / \mathrm{N}(\%)^{\mathrm{a}}$ & $\mathrm{n} / \mathrm{N}(\%)^{\mathrm{a}}$ \\
\hline Male & $96 / 181(53)$ & $119 / 226(53)$ & $215 / 407(53)$ \\
\hline Female & $85 / 181(47)$ & $107 / 226(47)$ & $192 / 407(47)$ \\
\hline Median age in years (interquartile range) & $26(22-33)$ & $1(0-9)$ & $15(1-26)$ \\
\hline Complications & 43/181 (24) & $29 / 226(13)$ & $72 / 407(18)$ \\
\hline Pneumonia & $28 / 43(65)$ & $23 / 29(79)$ & $51 / 72(71)$ \\
\hline Encephalitis & $1 / 43(2)$ & $1 / 29(3)$ & $2 / 72(3)$ \\
\hline Other & 14/43（33） & $5 / 29(17)$ & $19 / 72(26)$ \\
\hline Laboratory confirmation requested $^{b}$ & $143 / 181(79)$ & $169 / 226(75)$ & $312(77)$ \\
\hline IgM-positive, saliva & $9 / 143(6)$ & $11 / 169(7)$ & $20 / 312(6)$ \\
\hline IgM-positive, serum & $111 / 143(78)$ & 19/169 (11) & $130 / 312(42)$ \\
\hline PCR-positive & $60 / 143(42)$ & $153 / 169$ (91) & $213 / 312(68)$ \\
\hline Seroconversion & $26 / 143(18)$ & $7 / 169(4)$ & $33 / 312(11)$ \\
\hline Vaccination status unknown & $77 / 181(43)$ & 43/226 (19) & $120 / 407(29)$ \\
\hline Vaccination status known & $104 / 181(57)$ & $183 / 226 \quad(81)$ & $287 / 407(71)$ \\
\hline Not vaccinated $^{c}$ & $74 / 104(71)$ & $150 / 183(82)$ & $224 / 287(78)$ \\
\hline Vaccinated with one dose ${ }^{c}$ & $26 / 104(25)$ & $26 / 183(14)$ & $52 / 287(18)$ \\
\hline Vaccinated with two doses ${ }^{c}$ & 4/104（4) & $7 / 183(4)$ & $11 / 287(4)$ \\
\hline
\end{tabular}

a Unless otherwise specified.

More than one laboratory method could be used to confirm a single case.

Among cases whose vaccination status was known.

were clinically diagnosed with measles, or (ii) they were exposed to a measles case (patient or HCW), or (iii) they were susceptible to be frequently exposed to measles because of their workplace (i.e. emergency room), or (iv) they were potentially susceptible. Immunity status against measles was assessed by enzyme-liked immune-sorbent assay (ELISA) (Enzygnost ${ }^{\circledR}$ IgG Dade Behring, Siemens, France). Patients and HCW were considered immune if IgG titres were higher than $325 \mathrm{mIU} /$ $\mathrm{ml}$.

\section{Statistical analysis}

The qualitative variables are reported as number and percentage and the quantitative variables as median and interquartile range*. Characteristics of patients with measles were analysed for adults ( $>16$ years-old) and children ( $\leq 16$ years-old) separately. Qualitative variables were compared by using the chi-squared test. The significance level was p<0.05. Data from the notification sheet were recorded using EpiData. Statistical analyses were performed with Stata software (Stata Corp.) version 10.0 .

\section{Results}

Characteristics of the patients described from the mandatory notification

Overall, 407 measles cases were diagnosed in LUH between 1 January 2010 and 8 July 2011 (Figure 1). Of these 407 cases, 149 (37\%) were clinical suspected cases, 193 (47\%) were laboratory confirmed and $65(16 \%)$ were epidemiologically confirmed. Table 1 describes the characteristics of all cases diagnosed in LUH. Overall, the median age of cases was 15 years (interquartile range 1-26 years). The median age for adult cases ( $>16$ years-old) was 26 years (interquartile range 22-33 years) while the median age for cases who were children ( $\leq 16$ years-old) was one year (interquartile range 0-9 years). Among the cases, 192 (47\%) were female; 181 (44\%) were adults ( $>16$ years-old) and $226(56 \%)$ were children ( $\leq 16$ years-old). The age groups with the highest incidence involved children under one year of age $(n=129,32 \%)$ and $17-29$ yearolds ( $n=126,31 \%)$. Among the 129 children under one year of age, 75 (58\%) were male, 17 (13\%) infants presented complications (14 had pneumonia), and 25 (19\%) were hospitalised.

In total, 72 (18\%) presented complications: 51 (13\%) had pneumonia, two ( $11 \%)$ had encephalitis and 19 (5\%) had other complications. Other complications reported mainly involved the digestive system, like hepatitis or diarrhea, and infection of the ear-nose-throat area. No patient died because of measles. Vaccination status was available for 287 cases (71\%). Among them, 63 (22\%) were vaccinated, 52 (18\%) with a single dose of measles vaccine and 11 (4\%) with two doses. 
Virology and immunology data from the hospital virology-based surveillance

Overall, 2,763 individuals were tested by serology and/ or PCR in LUH: 1,398 (51\%) patients and 1,365 (49\%) HCW. Among 819 patients tested for IgM, $233(28 \%)$ were IgM-positive. Among 512 tested by PCR, 317 (62\%) were PCR-positive. Of 891 patients tested for IgG, 641 ( $72 \%$ ) were IgG positive (IgG titres $325 \mathrm{mIU} / \mathrm{ml})$. Figure 2 depicts the repartition by age groups, of the proportion of IgG positive among adults patients tested for IgG.

Among 1,227 HCW tested for IgM, 16 (1\%) were IgMpositive, none was PCR-positive, while for $1,365 \mathrm{HCW}$ tested for IgG, 1,304 (96\%) were IgG-positive (IgG titres`325 $\mathrm{mlU} / \mathrm{ml}$ ). Figure 3 describes the proportion of IgG-positive against measles among HCW by age. The proportion of patients aged up to 30 years who were not considered immune (IgG titres $\leq 325 \mathrm{mIU} / \mathrm{ml}$ ) was $38 \%$ vs $16 \%$ in patients older than 30 years ( $p<0.001$ ). The proportion of HCW up to 30 years of age who were not immune (IgG titres $\leq 325 \mathrm{mlU} / \mathrm{ml}$ ) was $11 \%$ vs $3 \%$ in $\mathrm{HCW}$ older than 30 years (p<o.001).

\section{Measles cases among pregnant women}

During the study period, 13 measles cases occurred among pregnant women. These cases occurred between January and July 2011. Among these women aged 25-45 years, seven were younger than 30 yearsold. Among the 13 cases, one developed measles in the first trimester of gestation, six developed measles in the second trimester, five in the third trimester and one developed measles in immediate post-partum. Six
(46\%) of the pregnant measles cases had to be hospitalised. Four patients (31\%) developed pneumonia as a consequence of the infection by measles, and one had a premature child.

\section{Control measures}

Various control measures were implemented to control the risk of hospital-acquired measles and to protect HCW. In LUH, when a case was reported to the infection control unit, an investigation was conducted to find details on this case's possible contacts with other patients or HCW. If necessary, specific prevention measures were implemented and adapted to the immune status of individuals. Patients and HCW, who had been in contact with measles cases during their infectious period, were informed about the risk of infection. People who were not immunised received a dose of measles vaccine or intravenous immune globulins, depending on their immune status, age or pregnancy status. Information about hygiene precautions was relayed by posters in all hospital wards, with special attention paid to emergency units. A questionnaire was delivered to $\mathrm{HCW}$ to ascertain their immune status. A blood sample was taken if immune status was unknown. If they had not received two vaccine doses, information about the high risk of transmission of the virus was delivered, and complementary vaccination was suggested. Moreover, a monthly measles surveillance report was performed by the infection control unit. This report summarised epidemiological data about the outbreak and was diffused via e-mail to all the HCW and to the hospital administration.

\section{FIGURE 2}

Proportion of IgG-positive against measles by age groups, among adult patients tested in Lyon University Hospitals, France, 1 January $2010-8$ July $2011(\mathrm{n}=691)$

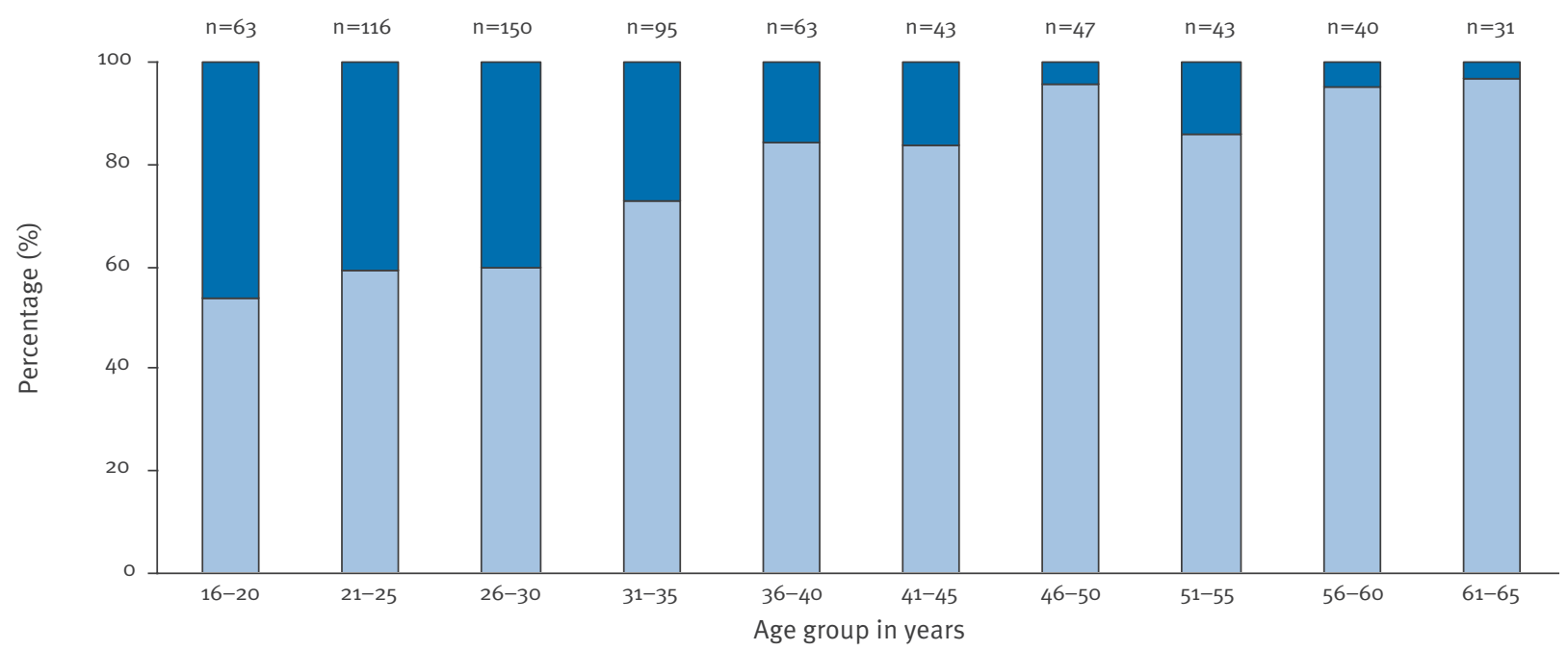

\begin{tabular}{llllllllll}
$\square$ \% IgG negative & 46 & 41 & 40 & 27 & 16 & 16 & 4 & 3 \\
\hline$\%$ IgG positive & 54 & 59 & 60 & 73 & 84 & 84 & 96 & 86
\end{tabular}


Proportion of IgG-positive against measles by age groups among healthcare workers tested in Lyon University Hospitals, France, 1 January 2010-8 July $2011(n=1,365)$

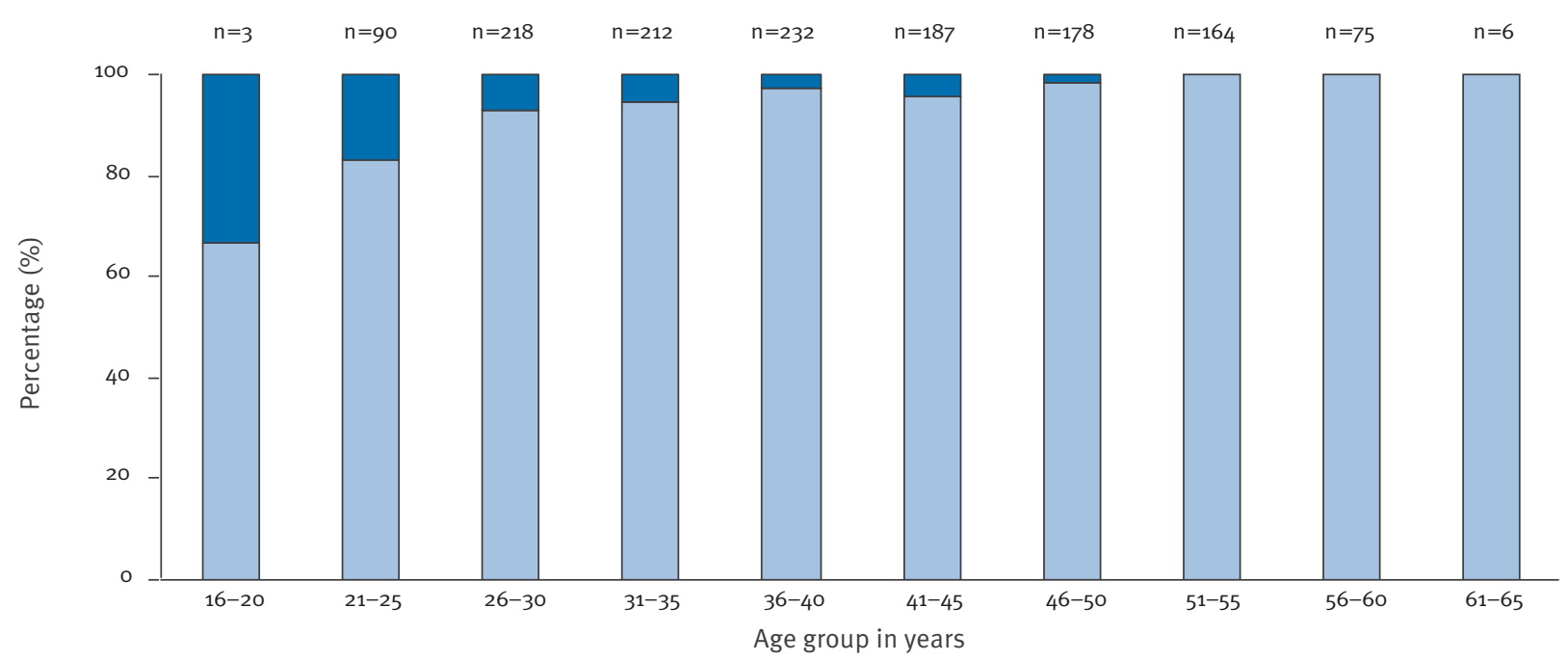

\begin{tabular}{llllllllll}
$\square \%$ IgG negative & 33 & 17 & 7 & 6 & 3 & 4 & 2 & 0 \\
\hline$\square$ IgG positive & 67 & 83 & 93 & 94 & 97 & 96 & 98 & 100 & 100
\end{tabular}

\section{Discussion and conclusion}

It was estimated in 2009 that eight percent of people aged between six and 29 years were not immunised against measles in France [12]. The coverage is under the threshold of $95 \%$ needed for measles elimination [13]. The objective of this study was to describe the measles outbreak which occurred in Lyon, located in the Rhône-Alpes area, from 2010 to mid 2011. Our analysis focused on patients diagnosed with measles in LUH, pregnant women and HCW, and on virology and immunology data from the hospital virology-based surveillance. Overall, 407 cases of measles were diagnosed in LUH. According to 2009 estimations 92 percent of individuals between six and 29 years-old were immunised in France [12]. Moreover, in 2010-2011, the vaccination coverage for measles at 24 monthsold ( 1 dose) was $88.8 \%$ in the Rhône-Alpes region [11]. Consequently, IgG seropositivity rates among children and young adults under 30 years-old in the RhoneAlpes region but also nationwide are likely to reflect more vaccination coverage than contact with the virus. Although the tested population was a biased sample of the Lyon population, seroprevalence of IgG against measles was low, especially in patients and HCW under 30 years. Vaccination against measles is recommended but not mandatory for HCW in France. Their risk to contract measles appears to be much higher than the general population and they can potentially transmit the disease to their patients, especially the immunocompromised ones [14]. It appears urgent to reach a higher vaccination coverage with two doses in the French population. Eliminating measles is one of the World Health
Organization's goal, which is expected for 2015 [15]. According to the results of our study, overall $78 \%$ of the measles cases were not vaccinated. A report based on French mandatory notifications between January 2008 and April 2011 [2] found similar rates concerning lack of vaccination: $86 \%$ of the cases did not receive the measles, mumps, and rubella (MMR) vaccine against measles, with differential compliance and immunisation coverage in the various districts of France. It pointed out that communications towards the general population about the need to be vaccinated in order to be protected, have to be strengthened.

Attention must be paid to newborns under one year of age because they are too young to be vaccinated and may no longer be protected by maternal antibodies. At the age of six months, $90 \%$ of the infants are not protected, irrespective of the mother's immunisation status [16]. Measles acquired during pregnancy can have deleterious effect on the mother and child outcome [17]. The most serious and frequent complication reported for pregnant women is pneumonia [17-20]. The hospitalisation and case fatality rates among pregnant women may be higher than among non-pregnant adults [20]. Concordant with these data, four cases of pneumonia among 13 pregnant cases were found in our study. Six of the pregnant women were hospitalised. An increased risk of foetal and neonatal loss is also reported [17-20]. In one case observed in this study, a premature birth occurred, however it could have been attributable to other causes. Some authors also reported an increased risk of subacute sclerosing 
panencephalitis following neonate [21] or congenital [22] measles infection. Women in childbearing age should be informed of the risk of contracting measles and its possible complications. Vaccination that can only assure protection should be proposed as soon as possible in pre- or post-partum. Measles among pregnant women should be no longer considered uncommon in the regions that report outbreaks and should be systematically considered in the context of pregnant women presenting to a health practitioner with pneumonia.

In comparison with other European countries, France has been the most affected with 13,957 cases reported between January and August 2011 [9]. Italy, who reported 4,300 measles cases during the same period was the second most affected European country [6]. Four measles cases among pregnant women were reported [6] and $36 \%$ of cases were hospitalised. Overall $14 \%$ presented complications [6], which was in concordance with the complication rate of $18 \%$ in the Lyon area. Romania also experienced a large measles outbreak in 2011, with 2,072 reported cases [8]. The complication rate in Romania was much higher than in the Lyon area (respectively, $39 \%$ and $18 \%$ ). Finally, the Geneva canton in Switzerland, which neighbours the Rhône-Alpes region, only reported 41 measles cases between January and May 2011, so it was far less affected than Rhône-Alpes area [5]. There, serious control measures, with quarantining and a vaccination campaign were systematically implemented. The larger number of cases that we experimented during the outbreak in Lyon area did not prevent carrying out a vaccination campaign, however, quarantining each measles case was more difficult to implement.

The main limitation of our study was a possible underestimation of the true measles incidence, as, in France, about $50 \%$ of measles cases were not reported on mandatory notification [10]. However this should not bias time-trends. Moreover, we were unable to calculate its incidence per 1,000 inhabitants because the exact origin of individuals was not known.

In conclusion, catch-up vaccination campaigns should focus on individuals aged under 30 years-old who have not received two doses of measles vaccine and on HCW. The outbreak is likely to re-occur, especially in the regions of France with low vaccine coverage. Clusters of susceptible individuals accrued over the years $[10,11]$. Indeed, the French Institute for Public Health Surveillance (InVS) reported that among children of 24 months old in 2008 , only $90 \%$ had received one dose of the measles vaccine while according to the French vaccination programme, they should have already got two doses [23]. A fourth epidemic wave has to be expected in France and Europe. Hospitalbased surveillance of measles is relevant to estimate the spread of the disease in the community and to help with early detection of healthcare-acquired cases.
* Authors' correction:

At the request of the authors, the sentence 'Quantitative variables were described as number and percentage, and qualitative variables as median and interquartile range.' was changed to 'The qualitative variables are reported as number and percentage and the quantitative variables as median and interquartile range.'. This change was made on 10 September 2012.

Acknowledgments

We thank the Agence Régionale de Santé de Rhône-Alpes (AM McKenzie, G Courbis) for their contribution to our surveillance of measles cases at Lyon University Hospitals. We thank F Champion, A Fichez, S Blanc, K Bellemin, C Volckmann, A Duvermy, MA Denis, P Nargues, JB Fassier, for their contribution to the hospitalised-based surveillance of measles cases. Manuscript editing by Ovid Da Silva is acknowledged. 


\section{References}

1. Haut Conseil de la santé publique (HCSP). Avis relatif à l'actualisation des recommandations vaccinales contre la rougeole pour les adultes. 11 février 2011. [Notice on update of recommendations for measles vaccinations in adults]. Paris: HCSP; 11 Feb 2011. French.

2. Baudon C, Parent du Châtelet I, Antona D, Freymuth F, Poujol I, Maine C, et al. Caractéristiques de l'épidémie de rougeole démarrée en France depuis 2008 : bilan des déclarations obligatoires pour les cas survenus jusqu'au 30 avril 2011. [Characteristics of the measles epidemic in France which began in 2008: a review of mandatory reporting for cases occuring until 30 April 2011]. Bull Epidémiol Hebd. 2011;33-34:353-8. French.

3. Benkimoun P. Outbreak of measles in France shows no signs of abating. BMJ. 2011;342:d3161.

4. Six C, Blanes de CJ, Duponchel J, Lafont E, Decoppet A, Travanut M, et al. Spotlight on measles 2010: Measles outbreak in the Provence-Alpes-Cote d'Azur region, France, January to November 2010 - substantial underreporting of cases. Euro Surveill. 2010;15(50):pii=19754. Available from: http://www.eurosurveillance.org/ViewArticle. aspx?Articleld=19754

5. Delaporte E, Richard JL, Wyler Lazarevic CA, Lacour O, Girard M, Ginet C, et al. Ongoing measles outbreak, Geneva, Switzerland, January to March 2011. Euro Surveill. 2011;16(10):pii=19815. Available from: http://www. eurosurveillance.org/ViewArticle. aspx?Articleld $=19815$

6. Filia A, Tavilla A, Bella A, Magurano F, Ansaldi F, Chironna M, et al. Measles in Italy, July 2009 to September 2010. Euro Surveill. 2011;16(29):pii=19925. Available from: http://www. eurosurveillance.org/ViewArticle.aspx?Articleld $=19925$

7. Sabbe M, Hue D, Hutse V, Goubau P. Measles resurgence in Belgium from January to mid-April 2011: a preliminary report. Euro Surveill. 2011:16(16):pii=19848. Available from: http:// www.eurosurveillance.org/ViewArticle.aspx?Articleld $=19848$

8. Stanescu A, Janta D, Lupulescu E, Necula G, Lazar M, Molnar $\mathrm{G}$, et al. Ongoing measles outbreak in Romania, 2011. Euro Surveill. 2011;16(31):pii=19932. Available from: http://www. eurosurveillance.org/ViewArticle.aspx?Articleld =19932

9. European Centre for Disease Prevention and Control (ECDC). Surveillance report. European monthly measles monitoring. Stockholm: ECDC. Sep 2011. Available from: http://ecdc. europa.eu/en/publications/Publications/111018_EMMO SEPT_2011.pdf

10. Parent du Châtelet I, Antona D, Freymuth F, Muscat M, Halftermeyer-Zhou F, Maine C, et al. Spotlight on measles 2010: update on the ongoing measles outbreak in France, 2008-2010. Euro Surveill. 2010;15(36):pii=19656. Available from: http://www.eurosurveillance.org/ViewArticle. aspx?Articleld $=19656$

11. Dennetiere G, Fort B. Rougeole en Rhône-Alpes. Point sur la vague épidémique d'octobre 2010 à septembre 2011. [Measles in Rhône-Alpes. Sum up on the situation regarding the epidemic wave from October 2010 to September 2011]. Bulletin de veille sanitaire Rhône-Alpes. Numero special rougeole. 14 Nov 20122. French. Available from: http://www.invs.sante.fr/ Publications-et-outils/Bulletin-de-veille-sanitaire/Tous-lesnumeros/Rhone-Alpes/Bulletin-de-veille-sanitaire-RhoneAlpes.-Numero-special-rougeole

12. Lepoutre A, Antona D, Fonteneau L, Baudon C, HalftermeyerZhou F, Le Strat Y, et al. Enquête nationale de séroprévalence des maladies infectieuses 2009-2010, 1er résultats. Communication orale, 12ème Journées Nationales d'Infectiologie, Toulouse 2011. [National seroprevalence survey of infectious diseases 2009-2010, the first results. Oral communication, 12th National Symposium on Infectious Diseases, Toulouse 2011]. Med Mal Inf. 2011;41(6):suppl.1. French.

13. Centers for Disease Control and Prevention (CDC). Increased transmission and outbreaks of measles - European Region, 2011. MMWR Morb Mortal Wkly Rep. 2011;60(47):1605-10.

14. Botelho-Nevers E, Cassir N, Minodier P, Laporte R, Gautret $\mathrm{P}$, Badiaga S, et al. Measles among healthcare workers: a potential for nosocomial outbreaks. Euro Surveill. 2011;16(2): pii=19764. Available from: http://www. eurosurveillance.org/ViewArticle.aspx?Articleld=19764

15. World Health Organization (WHO) - Regional office for Europe. Eliminating measles and rubella. Framework for the verification process in the WHO European Region. 2012. WHO Regional Office for Europe: Copenhagen; 2012. Available from: http:// www.euro.who.int/_data/assets/pdf_file/0003/158304/ EURO_MR_Elimin_Verification_Processv2.pdf

16. Gagneur A, Pinquier D. Letter to the editor. Spotlight on measles 2010: timely administration of the first dose of measles vaccine in the context of an ongoing measles outbreak in France. Euro Surveill. 2010;15(41):pii=19689. Available from: http://www.eurosurveillance.org/ViewArticle. aspx?Articleld=19689

17. Manikkavasagan G, Ramsay M. The rationale for the use of measles post-exposure prophylaxis in pregnant women: a review. J Obstet Gynaecol. 2009;29(7):572-5.

18. Ali ME, Albar HM. Measles in pregnancy: maternal morbidity and perinatal outcome. Int J Gynaecol Obstet. 1997;59(2):109-13.

19. Chiba ME, Saito M, Suzuki N, Honda Y, Yaegashi N. Measles infection in pregnancy. J Infect. 2003;47(1):40-4.

20. Eberhart-Phillips JE, Frederick PD, Baron RC, Mascola L. Measles in pregnancy: a descriptive study of 58 cases. Obstet Gynecol. 1993;82(5):797-801.

21. Sawaishi Y, Abe T, Yano T, Ishikawa K, Takada G. SSPE following neonatal measles infection. Pediatr Neurol. 1999;20(1):63-5.

22. Cruzado D, Masserey-Spicher V, Roux L, Delavelle J, Picard F, Haenggeli CA. Early onset and rapidly progressive subacute sclerosing panencephalitis after congenital measles infection. Eur J Pediatr. 2002;161(8):438-41.

23. Institut de Veille Sanitaire (InVS). Couverture vaccinale rougeole: La couverture vaccinale à 24 mois. [Measles vaccination coverage among infants aged 24 months-old]. Paris: InVS. 13 Apr 2010. French. Available from: http:// www.invs.sante.fr/Dossiers-thematiques/Maladiesinfectieuses/Maladies-a-declaration-obligatoire/Rougeole/ Couverture-vaccinale-rougeole. 